\title{
A Cross Section Study to Correlate Fine Needle Aspiration Cytology and Histopathology in the Diagnosis of Parotid Tumours at Four Major Hospitals in Zambia
}

\author{
Kazuma S. M. E. ${ }^{1}$, Mucheleng'anga L. ${ }^{2}$ Zulu R. ${ }^{3}$ Hanna H. ${ }^{4}$ \\ ${ }^{1}$ General Surgery Registrar at University Teaching Hospital; Master of Medicine \\ final year General Surgery Trainee (UNZA); MCS (ECSA); FCS (ECSA) General \\ Surgery Trainee \\ ${ }^{2}$ Pathologist at Univ ersity Teaching Hospital, MMED Pathology (UNZA) \\ ${ }^{3}$ Consultant General Surgeon at University Teaching Hospital, MRCS, MMED \\ General Surgery (UNZA), FCS (ECSA) General Surgery \\ ${ }^{4}$ Professor of General Surgery, PHD General Surgery, MMED General Surgery, \\ MRCS
}

Correspondence to: Dr. M. E Kazuma Seke, Email: sekekazuma@gmail.com https://dx.doi.org/10.4314/ecajs.v22i1.12

Background: Needle Aspiration Cytology (FNAC) is cheap, simple, quick, minimally invasive procedure that is widely used for preoperative diagnosis of Parotid tumours.

Methods: Twenty five patients were prospectively studied over a two-year period at four major hospitals in Zambia. FNAC was done using a 10cc syringe and 20-22G needles for sample collection and specimen staining was done with papanicolaou stain. Histopathology was assessed with Haematoxylin and Eosin (H\&E) stained sections.

Results: FNAC correlated with histopathology with a sensitivity of $100 \%$ and specificity of 66.7\%; positive and negative predictive values of $95.7 \%$ and $100 \%$ respectively and a likelihood ratio of 3. All Parotid tumours were neoplastic with $76 \%$ benign and $24 \%$ malignant tumours on histopathology. FNAC accurately diagnosed $68 \%$ benign and $20 \%$ malignant tumours.

Conclusion: This study found that FNAC correlates well with histopathology in the diagnosis of parotid tumours. FNAC is useful in the preoperative assessment of Parotid tumours as it provides a preoperative diagnosis that influences management by either avoiding surgery (inflammatory lesion) and limiting the extent of surgery for benign and malignant Parotid tumours.

\section{Introduction}

George Papanicolaou (1883-1962) is generally accredited for use of cytopathological examination of cells for diagnosis of tumours. FNAC involves subjecting appropriately stained aspirated cells to cytopathological examination where the cells are evaluated for morphological changes based on the appearance of individual cells or cell clusters ${ }^{9}$. Theoretically this procedure is supposed to diagnose most tumours with acceptable sensitivity and specificity. 
Salivary gland tumours make up $10 \%$ of all head and neck tumours (parotid gland tumours contribute $2-6.5 \%$ ) and $3 \%$ of all tumours of the body $4,9,10,11$. There are two types of Salivary glands, major (parotid, submandibular and lingual) and minor salivary glands ${ }^{1}$. The parotid gland tumours are 10 times more common than submandibular tumours and 100 times more common than lingual tumours. $80 \%$ of parotid tumours are benign ${ }^{1}$.

The incidence of parotid gland tumours is $1-2 / 100,000^{1}$. There is equal incidence between the sexes ${ }^{1}$. Risk factors for development of parotid gland tumours include nutritional deficiencies, exposure to radiation, ultra-violet exposure, genetic predisposition and infection with Epstein-Barr virus ${ }^{1}$.

Generally, it has been accepted among Head and Neck Surgeons that tumours of the parotid gland, present management problems for various reasons ${ }^{4,11}$. In the first instance, most surgeons believe that the presence of a parotid gland tumour is an indication for removal ${ }^{4,9,11}$. Clinical diagnosis has been used to preoperatively diagnose and influence surgical management of a patient with a parotid gland tumour. But it is difficult to distinguish clinically between inflammatory and non-inflammatory lesions or between benign and malignant lesions ${ }^{1}$. This is because inflammatory lesions are not subjected to surgery but conservative management ${ }^{1,4,9}$. Clinical diagnosis has resulted in over treatment of patients with inflammatory parotid tumours which have been subjected to surgery and under treatment of patients with malignant parotid lesions that have been treated by parotid conserving surgery ${ }^{4,9,11}$. Clinical diagnosis cannot decide the fate of the facial nerve, whether to excise or not, excision of facial nerve with its consequence of facial nerve paralysis has resulted in increased morbidity ${ }^{1,4,9,11}$.

It remains a challenge to obtain a preoperative tissue diagnosis of the parotid gland tumour because salivary gland tumours are not subject to conventional tissue diagnosis by core needle biopsy or incisional biopsy as these complicate into formation of salivary fistulae and implantation of malignant tumours ${ }^{1,4}, 9,10,11,12$. Secondly, a preoperative diagnosis ensures planning of the surgical procedure to be done (whether conservative or total parotidectomy and whether to do neck dissection or not in the case of malignant tumours) $)^{1,4,9,10,11,12}$. However, lack of a preoperative diagnosis poses a challenge to appropriately counsel patients about the preoperative diagnosis and prognosis and what procedure is to be done and whether or not the facial nerve will be preserved ${ }^{4}$.

Thirdly, an intraoperative diagnosis at the time of surgery by assessment of frozen sections is not readily available even in developed centres and they are not available in resource limited centres especially in the developing world like Zambia ${ }^{4,9,12}$.

In view of the above, FNAC has gained popularity among Head and Neck surgeons who have used this procedure to preoperatively diagnose Head and Neck Tumours ${ }^{4,9}$. The application of FNAC for diagnosis of Parotid gland tumors has been an area that has been widely debated $^{4}, 5,9,10,11$. The management problems of patients with parotid gland tumours has led to more research being done about the application of FNAC in obtaining a preoperative tissue diagnosis ${ }^{4}$. As a result, FNAC has established its role in the diagnosis of parotid gland 
tumours $1,4,5,8,9,10,11,12$. Those who support FNAC use in the preoperative diagnosis argue that FNAC can distinguish neoplastic from non-neoplastic lesions, and benign from

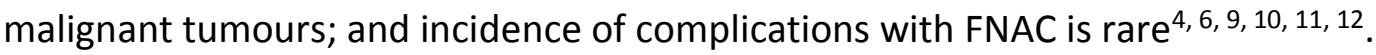

Those who argue against the use of FNAC in the diagnosis of parotid gland tumours feel that FNAC has low sensitivity in the diagnosis of parotid gland malignant tumours, and that it only changes the management of lymphomas of the parotid gland ${ }^{4,18}$. They argue that FNAC obscures diagnosis, there is increased incidence of inadequate sampling therefore, it requires multiple sampling, prolongs the period of waiting for operative management and therefore increases the cost of hospital stay ${ }^{18}$. The Value of FNAC in the investigation of salivary gland disease has also been widely discussed by both Clinicians and Cytopathologists $4,9,10,11$. Most Clinicians argue that FNAC is not accurate enough to diagnose parotid gland tumours and therefore influence decision making in terms of whether to operate or not to operate ${ }^{4,12}$.

An audit of the parotid gland surgeries was performed at University Teaching Hospital (UTH) between August 2013 and September 2014. A total of 14 parotid gland surgeries were done for parotid gland tumours. $79 \%$ were superficial Parotidectomies and $21 \%$ were total Parotidectomies. None of the patients had a preoperative tissue diagnosis to objectively ascertain the extent of the surgery in order to avoid over or under treatment. Only $14 \%$ had a post-operative diagnosis the rest had missing excised parotid samples, either they were taken to other laboratories or the samples were lost. It cannot be objectively stated whether we are treating our patients optimally or not from the above statistics. In this era of patients being aware about their rights, this is a recipe for litigation because the consequences of not optimally treating patients are grave. This is the more reason why we need to conduct our own studies on how we can achieve a preoperative diagnosis of the parotid gland tumours and determine whether surgical intervention is required or not and if it is required then to what extent should it be done. In short we need to practice evidence based medicine.

This study was aimed at evaluating the diagnostic accuracy of FNAC of parotid gland tumours by correlating it with Histopathological diagnosis. At the time of operation and with obtained informed consent, an FNAC sample of the parotid gland tumour planned for excision was obtained while the patient was under anesthesia. The excised parotid gland tissue was also kept after surgery. Cytopathological and Histopathological examinations were performed by different pathologists to avoid bias. The diagnoses of the two in the same specimen was evaluated for accuracy. In this case histopathology was considered the gold standard and therefore became the control.

If the correlation between FNAC and Histopathology was significant then a cytopathological preoperative diagnosis can start the initial treatment of patients with parotid gland tumours and it can influence the management of patients with parotid gland tumours to avoid excess morbidity associated with over treatment of parotid gland tumours. The general objective of this study was to determine the correlation of FNAC and histopathology in the diagnosis of parotid tumors at University Teaching Hospital in Lusaka, Chipata Central Hospital in 


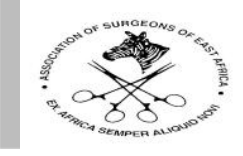

Chipata, Livingstone Central Hospital in Livingstone and Ndola Teaching Hospital in Ndola, Zambia. The specific_objectives were to determine the specificity and sensitivity of FNAC; and calculate the positive and negative predicitive values, and likelihood ratio of FNAC in the diagnosis of Parotid Tumours; and to determine the usefulness of FNAC in the management of Parotid tumours.

\section{Patients and Methods}

This was a prospective study done in the Departments of Surgery at the University Teaching Hospital (Lusaka), Ndola Teaching Hospital (Ndola), Chipata Central Hospital (Chipata) and Livingstone Central Hospital (Livingstone); from April 2014 to October 2016. A total of 25 patients with parotid tumours were recruited in this study and all were later operated. All the 25 patients were subjected to thorough history and physical examination with appropriate imaging. A preoperative FNAC was done either in the clinic, on the ward or just before operation under General anesthesia in theatre depending on patients' preferences. The postoperative excision samples were submitted for histopathological diagnosis.

FNAC was done using a $10 \mathrm{cc}$ syringe and a $20-22 \mathrm{G}$ needle in a patient who had given an informed consent. The smears were done on 6 glass slides, 3 were fixed in alcohol and 3 were air dried, then stained with papanicolaou stains, subsequently reported. The postoperative excision samples were fixed in 10\% formalin and then gross and microscopic examinations performed after staining with H\&E stains. The FNAC and Histopathology reports were then retrospectively reviewed, compared and analyzed. A comparison of preoperative FNAC and post-operative histopathology diagnosis was done and the data analysis was performed by calculating the sensitivity and specificity, likelihood ratio and positive and negative predictive values of FNAC in the diagnosis of Parotid tumours.

\section{Results}

The study population was comprised of 25 patients who had had preoperative samples collected for FNAC and had a final Histological post-operative diagnosis. Eleven were males and 14 were females giving a male to female sex ratio of 1: 1.3. Their ages ranged from 19 to 74 years with a mean of 40.6 years and a median age of 34 years.

Figure 1 shows the age distribution of patients in the study. Figure 2 shows the diagnoses made on histopathology. Commonest tumour was pleomorphic adenoma at 52\%.

FNAC did not correlate with 3 specimens which were diagnosed as 1 chronic sialadenitis (wrong diagnosis, histopathology showed invasive squamous cell carcinoma); and 2 samples which were acellular. Based on this data the following calculations were done based on Table 3. 
Table 1. The FNAC and Histological diagnoses of the patients involved in the study.

\begin{tabular}{|c|c|c|c|c|c|c|}
\hline No & Sex & Age & FNAC diagnosis & Histological diagnosis & $\begin{array}{c}\text { Positivity } \\
\text { status }\end{array}$ & $\begin{array}{c}\text { Negativity } \\
\text { Status }\end{array}$ \\
\hline 1 & $\mathrm{~F}$ & 35 & Pleomorphic adenoma & Pleomorphic adenoma & TP & \\
\hline 2 & $M$ & 29 & $\begin{array}{l}\text { lymphocytes/acini/ } \\
\text { myoepithelial Cells }\end{array}$ & Iymphoepithelial Cyst & TP & \\
\hline 3 & $\mathrm{~F}$ & 19 & $\begin{array}{l}\text { lymphocytes/acini/ } \\
\text { myoepithelial Cells }\end{array}$ & lymphoepithelial Cyst & TP & \\
\hline 4 & $M$ & 44 & $\begin{array}{l}\text { Acellular/unsatisfactor } \\
\text { y }\end{array}$ & lymphoepithelial Cyst & & FN \\
\hline 5 & $\mathrm{~F}$ & 68 & Pleomorphic adenoma & Pleomorphic adenoma & TP & \\
\hline 6 & $\mathrm{~F}$ & 29 & Carcinoma & $\begin{array}{l}\text { Epithelial-myoepithelial } \\
\text { carcinoma }\end{array}$ & TP & \\
\hline 7 & $\mathrm{~F}$ & 34 & $\begin{array}{l}\text { Acellular/unsatisfactor } \\
\text { y }\end{array}$ & lymphoepithelial Cyst & & FN \\
\hline 8 & $\mathrm{~F}$ & 45 & Pleomorphic adenoma & Pleomorphic adenoma & TP & \\
\hline 9 & $\mathrm{~F}$ & 35 & Pleomorphic adenoma & Pleomorphic adenoma & TP & \\
\hline 10 & $\mathrm{~F}$ & 15 & Pleomorphic adenoma & Pleomorphic adenoma & TP & \\
\hline 11 & $\mathrm{~F}$ & 84 & Pleomorphic adenoma & Pleomorphic adenoma & TP & \\
\hline 12 & $\mathrm{~F}$ & 22 & Pleomorphic adenoma & Pleomorphic adenoma & TP & \\
\hline 13 & $M$ & 28 & Pleomorphic adenoma & Pleomorphic adenoma & TP & \\
\hline 14 & $M$ & 30 & Pleomorphic adenoma & Pleomorphic adenoma & TP & \\
\hline 15 & $M$ & 68 & Carcinoma & Invasive SCC & TP & \\
\hline 16 & $M$ & 28 & $\begin{array}{l}\text { lymphocytes/acini/ } \\
\text { myoepithelial Cells }\end{array}$ & Iymphoepithelial Cyst & TP & \\
\hline 17 & $M$ & 56 & Carcinoma & Invasive SSC Metastatic & TP & \\
\hline 18 & $\mathrm{~F}$ & 40 & $\begin{array}{l}\text { lymphocytes/acini/ } \\
\text { myoepithelial Cells }\end{array}$ & Iymphoepithelial Cyst & TP & \\
\hline 19 & $M$ & 71 & Carcinoma & Invasive SCC & TP & \\
\hline 20 & $\mathrm{~F}$ & 74 & Carcinoma & Invasive SCC & TP & \\
\hline 21 & $\mathrm{~F}$ & 31 & Pleomorphic adenoma & Pleomorphic adenoma & TP & \\
\hline 22 & $M$ & 23 & Pleomorphic adenoma & Pleomorphic adenoma & TP & \\
\hline 23 & $M$ & 19 & Pleomorphic adenoma & Pleomorphic adenoma & TP & \\
\hline 24 & $\mathrm{~F}$ & 19 & Pleomorphic adenoma & Pleomorphic adenoma & TP & \\
\hline 25 & $M$ & 69 & Chronic Sialadenitis & metastatic carcinoma & & $\mathrm{FN}$ \\
\hline
\end{tabular}

Key: TP $=$ True Positive. $\quad$ FP= False Positive. $\quad$ FN = False Negative 
Table 2. Analysis of non-neoplastic and neoplastic tumours in the study.

\begin{tabular}{|c|c|c|c|}
\hline & $\begin{array}{c}\text { Histological } \\
\text { Diagnosis }\end{array}$ & $\begin{array}{c}\text { Cytological } \\
\text { Diagnosis }\end{array}$ & \\
\hline \multicolumn{4}{|l|}{ Benign Lesions } \\
\hline $\begin{array}{l}\text { Pleomorphic } \\
\text { adenoma }\end{array}$ & 13 & 13 & \\
\hline \multirow[t]{2}{*}{ lymphoepithelial Cyst } & 6 & 4 & $\begin{array}{c}\text { (2 samples wher } \\
\text { acellular) }\end{array}$ \\
\hline & 0.76 & 0.68 & \\
\hline \multicolumn{4}{|l|}{ Malignant lesions } \\
\hline \multirow[t]{2}{*}{ Carcinoma } & 6 & 5 & \\
\hline & 0.24 & 0.2 & \\
\hline \multicolumn{4}{|l|}{ Non- Neoplastic } \\
\hline \multirow[t]{2}{*}{ chronic sialadenitis } & 0 & 1 & $\begin{array}{l}\text { (wrong } \\
\text { diagnosis) }\end{array}$ \\
\hline & & 0.04 & \\
\hline
\end{tabular}

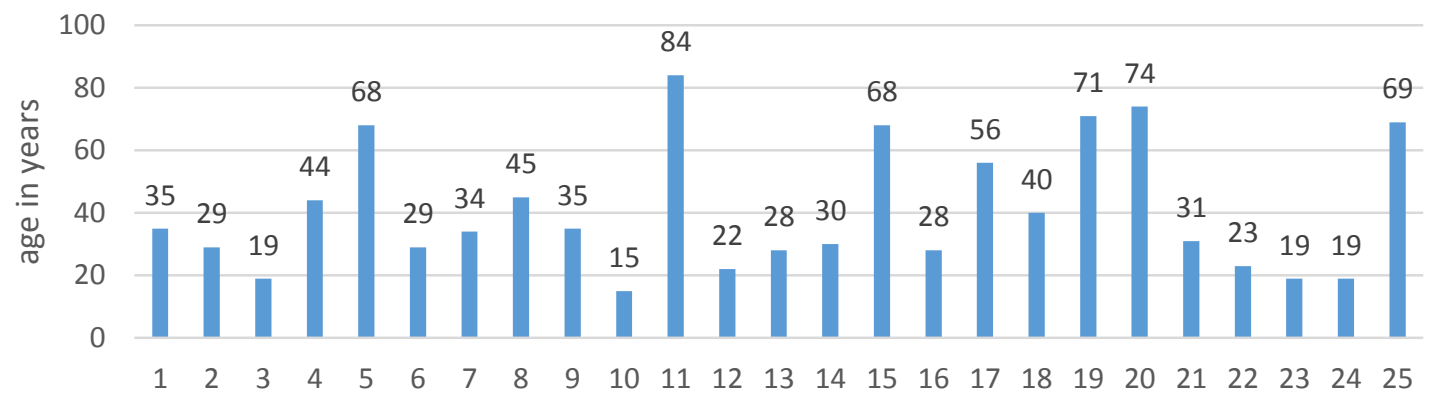

Figure 1. Age Distribution

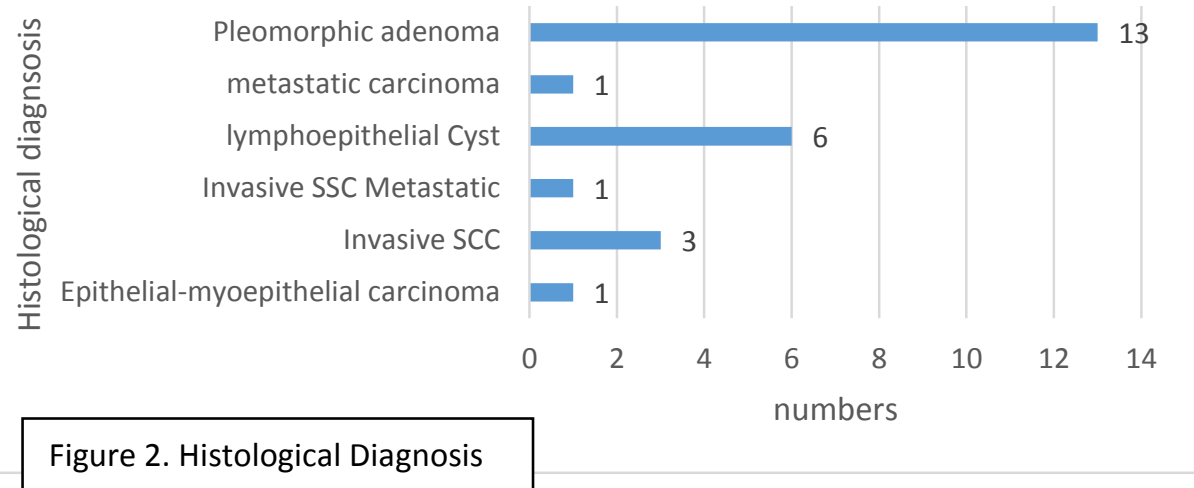




\section{Table 3.}

\begin{tabular}{|c|c|c|}
\hline & TRUE & FALSE \\
\hline Positive & $22(a)$ & $1(b)$ \\
\hline Negative & 0 c & 2 (d) \\
\hline
\end{tabular}

\section{Calculations}

Sensitivity $=a /(a+c)$

$$
22 /(22+0)
$$

$22 / 22$

$1.00(100 \%)$

Specificity $=\quad d /(b+d)$

$2 /(1+2)$

$2 / 3$

$0.6667(66.7 \%)$

Positive predictive value $=a /(a+b)$

$22 /(22+1)$

$22 / 23$

$0.9565(95.7 \%)$

Negative Predicative value $=d /(c+d)$

$2 /(0+2)$

$2 / 2$

$1.0(100 \%)$

Likelihood ratio $=\quad$ sensitivity/ (1-specifity)

$1.00 /(1-0.667)$

$1.00 / .3333$

3.003

3

The study showed that FNAC has a sensitivity of $100 \%$ and specificity of $66.7 \%$. The Positive Predictive value was $95.7 \%$ and the Negative Predictive value was $100 \%$. The Likelihood ratio was 3.

\section{Discussion}

FNAC is a safe, cheap and cost effective preoperative diagnostic procedure for assessment of Parotid tumours that offers a cytological diagnosis important in influencing management of Parotid tumours ${ }^{4,6}$. The management of parotid tumours involves an assessment of whether the Parotid tumour is inflammatory or neoplastic, and If neoplastic then whether benign or malignant. Inflammatory lesions are management conservatively while neoplastic tumours are subjected to surgery. ${ }^{4}$

Benign tumours of the Parotid gland in the superficial lobe are treated with superficial parotidectomy while those in the deep lobe are treated with total parotidectomy with facial 
nerve excision, while in some centres facial nerve sparing surgery is performed. Malignant tumours are treated with total parotidectomy with facial nerve excision ${ }^{4}$. Some centres perform superficial parotidectomies for malignant tumours in the superficial lobe with facial nerve sparing. All FNACs in the study were collected preoperatively few minutes or hours before the scheduled operations based on clinical assessment. All patients in the study had superficial parotidectomy with facial nerve sparing.

In this study, $88 \%$ of the samples from parotid tumours where diagnosed as neoplastic parotid tumours and $12 \%$ where unsatisfactory/acellular (2 out of 25) and wrong diagnosis (1 out of 25) on FNAC; while histology diagnosed $100 \%$ as neoplastic parotid tumours. FNAC diagnosed $68 \%$ as benign parotid tumours and $20 \%$ as malignant parotid tumours. Histopathology diagnosed $76 \%$ as benign parotid tumours and $24 \%$ as malignant parotid tumours. This finding is comparable with what other authors have found and reported benign tumours at $40 \%, 61 \%$ and $69 \%$; while malignant tumours have been reported at $6 \%$, $13 \%$ and $37 \%$. The commonest benign parotid tumour was pleomorphic adenoma at $52 \%$ on FNAC and Histopathology. FNAC was unable to characterize the malignant tumours and therefore reported as carcinoma but Histopathology showed Invasive squamous cell carcinoma as commonest malignant tumor of the parotid.

The age range was from 15 to 84 years. This shows that parotid tumours affects all age groups. Parotid tumours were seen more commonly in females than in males with a female to male ration of 1.2:1. Other studies have reported a ratio of 1.8:1 (F:M) ratio ${ }^{4}$. Pleomorphic adenoma was more common in females than in males at $69.2 \%$ of all pleomorphic adenomas. Carcinomas were more common in males than in females at $66.7 \%$ of all carcinomas in the study.

Two samples were acellular/unsatisfactory because of the cystic nature of the parotid tumours and therefore difficult to harvest any cells on aspiration. This phenomenon has been described by some authors and therefore a known weakness of FNAC ${ }^{4,6}$. Sometimes technique becomes important in ensuring proper sample collection otherwise the results maybe unsatisfactory necessitating repeating the procedure or the result maybe wrong altogether as was seen in one of the samples that showed chronic sialadenitis on FNAC but histopathology showed metastatic carcinoma. Sample collection on FNAC harvested necrotic tissue and inflammatory cells hence missing the diagnosis. This raises concern that FNAC requires proper technique of sample collection to ensure proper specimen that is representative of the tumour is collected. In this study, the sensitivity of FNAC was $100 \%$ while specificity was $66.7 \%$. Other authors have reported $57-98 \%$ sensitivity and specificity of $86-100 \%{ }^{4,6}$. The findings in this study are therefore comparable. The positive and negative predictive values were $95.7 \%$ and $100 \%$ respectively. This is very significant. The likelihood ratio was 3.03 which is very significant for the application of FNAC as a diagnostic test at the four centres were the study was conducted. The likelihood ratio of 3 increases the pretest probability that the positive result of FNAC will more likely indicate a correct pathology in the parotid gland of the patient and can therefore be adopted as an evaluation tool for preoperative assessment of parotid tumours at the four Hospitals in Zambia. 


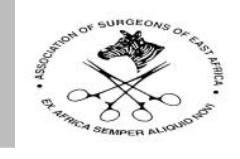

This study has shown that FNAC correlates with histopathology and therefore can be provide a preoperative cytological diagnosis which can influence management of patients parotid tumours in terms of whether to operate or not, and If a patient should be operated then what would be the extent of surgery and would the facial nerve be spared or not. Some patients in this study will have recurrences and therefore increased morbidity of reoperations for malignant tumours. This practice could be avoided in future by adopting preoperative cytological diagnosis of parotid tumours with FNAC. This shows that clinical assessment alone is not sufficient to evaluate parotid tumours and decide the extent of surgery. This study has shown the usefulness of FNAC and its potential to influence management of parotid tumours. The preoperative cytological diagnosis can guide the extent of surgery to be done and whether the facial nerve should be excised or spared. However, it has been shown that FNAC cannot give definitive diagnoses of some Parotid tumours compared to histopathology or but can determine whether the tumour is neoplastic or inflammatory and if neoplastic whether benign or malignant ${ }^{4}$.

\section{Conclusion}

This study has demonstrated that FNAC correlates with histopathology in the diagnosis of parotid tumours. FNAC is highly sensitive (100\%) and specific (66.7\%) and its usefulness as a cheap, cost effective, safe procedure in the evaluation of Parotid tumours has been demonstrated and that it can be relied upon to influence management of Parotid tumours. FNAC is therefore more reliable than clinical examination in distinguishing between malignant and benign parotid tumours.

\section{Recommendations}

FNAC should be adopted as a preoperative assessment procedure of evaluating Parotid tumours at the four major hospitals in Zambia.

\section{Acknowledgement}

We wish to recognize the following people for the support offered during the study: The Senior Medical Superintendents of University Teaching Hospital, Ndola Central Hospital, Livingstone Central Hospital and Chipata Central Hospital.

Miss Cooley for assistance in organizing patients for collection of samples from in theatre.

Mr. Chipaila for staining of all the FNAC specimen.

Dr. Maswabu and Dr. Shibemba and other pathologists at University Teaching Hospital for reading the Histology specimens.

\section{References}

1. Eugien N. Myers, Robert L. Ferris, (2007) SALIVARY GLAND DISORDERS, Springer.com, (Pdf) 
2. Norman S. Williams, Christopher Bulstrode and P. Ronan O'Connel, (2008) BAILEY AND LOVE'S SHORT PRACTRICE OF SURGERY, $25^{\text {th }}$ Edition, Holder Anold Publishers, Chapter 47, (Pdf)

3. Robert M. Zollinger, Jr. E. Christopher, ZOLLINGER'S ATLAS OF SURGICAL OPERATIONS, $9^{\text {th }}$ Edition, (Pdf)

4. A. Allam Choudhury, Tuhin Sultan, Belayat Hossain Siddique, A. Sufi Ahmed Amin, 'Diagnosis of Parotid Gland Mass by Fine Needle Aspiration Cytology (FNAC) nd its Histopathology Correlation, BSMMU, Daka, Bangladeshi, 2011, (2): 65-69

5. Chwee ML, Juliana T, Kwok SL, Siew SC, Lynne HYL, Luke KST. 'Role of fine-needle aspiration cytology in the evaluationof parotid tumours'. ANZJ. Surg, 2007; 77: 742-744.

6. Gordon TD, Kevin B, Roy A J S. An audit of surgery of the parotid gland. Ann R Coll Surg Engl, 1995; 77: 188-192.

7. Balakrishnan K, Mcmahon J, Imric J, Feeley KM, Parker AJ, Bull PD. Fine needle aspiration cytology in the management of a paroitid mass. A two centre retrospective study. The surgeon, 2005; 3:2: 67-72.

8. Howlett DC. Diagnosing a parotid lump: fine needle aspiration cytology or core biopsy? The british journal of Radiology, 2006;79: 295-297.

9. Kotwal M, Gaikwad S, R Patil, Munshi M, Bobhate S. FNAC of salivary gland - a useful tool in preoperative diagnosis or a cytopathogist's riddle? Journal of Cytology, 2007; 24:2:85-88.

10. Khandekar MM, Kavatkar AN, Patankar SA, Bagwan IB, Puranik SC, Deshmukh SD. 'FNAC of salivary gland lesions with histopathological correlation. India Journal of Otolaryngology and Head and Neck Surgery, 2006; 58:3:246-248.

11. Mohammed SI, Azharul I, Abdus S, Ekramuddula AFM, Hossain I H. 'Malignant salivary gland neoplasm clinicopathological study. Bangladesh J of Otorhinolaryngology, 2008; 14:1:1-5.

12. Attilio CS, Paolo C, Pierantonio B. Marco C. 'Usefulness of fine-needle aspiration in parotid diagnostics. Oral Maxillofac Surg, 2009;13:185-190.

13. Cristallinin EG, Ascani S, Farabi R. Fine Needle aspiration biopsy of salivary gland. Acta Cytol, 1997;41:5: 1421-1425

14. Ademar T J, Danyel E C, Jose M, Oslei P A, Luiz P K. Giant pleomorphic adenoma of the parotid gland. Med Oral Patol Oral Cir Bucal, 2008; 13:1. 58-60.

15. Reneton R, Gleave EN, Hancock BD, follow up of over 100 patients with salivary gland tumours treated in a single centre. BR. J Surg, 1996; 83 (17): 50-4

16. Qizilbash AH, Sianos J, Joug JEM, Archibalod SD, fine needle biopsy of major salivary glands. Actal Cytol 1985; 29: 503-12

17. Young JA, Diagnostic problems in fine needle aspiaration cytopathology of salivary glands. J Chin Pathol 1994; 47: 193-8

18. Robert L. Schmidt, Brian J. Hall, Andrew R. Wilson, MStat ad Layfield, A Systematic Review and Meta-Analysis of Diagnostic Accuracy of Fine Needle Aspiration Cytology for the Parotid Gland lesions, Am J Clin Panthol 2011; 136: 45-49

19. Batsaki JG, Sneige N, et Naggar AK, Fine Needle Aspiration Cytology Of Salivary Glands: its Utility and tissue effects. Ann Otol Laryngol. 1992; 101 (2 pt 1): 185-188. 